\title{
The Effect of a Sleep Hygiene Program on Older Adults
}

\author{
* Hemat Abd Elmoneem and** Amal I. Fouad \\ * Assistant Professorof Community Health Nursing,Faculty of Nursing, Ain ShamsUniversity/Egypt \\ ** Lecturerof Geriatric Health Nursing,Faculty of Nursing, Fayoum University/Egypt
}

\begin{abstract}
:
Background: Defaulting initiating sleeping (Insomnia) affectsthe daily lives of millions ofelderly people around the world and the most common sleeping disorder. Sleep hygiene practices encompasses a variety of behaviors and environmentalfactors that may affect sleep quality.

Aim of the study: The present study aimed to evaluate the effect of a sleep hygiene program on older adults. Design:A quasi-experimental design.

Settings: This study was conducted at Dar El Safa \& Dar Elmarwa geriatric homes in Heliopolis area. This setting was chosen for its high density with a total number (124).

Sample:A purposive sample was used to conduct this study, the sample size was 67(25 male and 42 female), they were chosen according to inclusion criteria.

Tools: two tools were used in the present study; a structured interview questionnaire \& the Pittsburgh sleep quality index (PSQI).

Results: The results Shows that the age of the studied elderly ranged between $60 \leq 70$ years, with the mean $\mathbf{6 6 . 5}$ \pm 3.29 , \& $62.7 \%$ were females. There was asignificant statistical difference in mean scores of sleep latency as reported by the studied elderly pre and post program. Also significant improvement in sleep onset latency mean score which was $50 \pm 25$ minutes pre-program compared to $21 \pm 13$ post-program at $P<0.05$. The same results indicates statistically significant positive correlations between the score of sleep hygiene practice and global PSQL Score at the pre $R=0.0473$ and post $R=0.681$ program phases.

Conclusion: The designed sleep hygiene program had statistically significant improvement in elderly knowledge and practices. Indeed, there was no statistically significant correlation between elderly' sleep hygiene knowledge and their Global Pittsburgh Sleep Quality Index (PSQI) Score at the pre and post intervention phases.

Recommendations: Educational programs for elderly individuals with insomnia toimprove their sleep quality with more efforts to improve the awareness of the elderly regarding theimportance of sleephygiene and the avoidance of risk factors of insomnia through posters, pamphlets, and booklets.
\end{abstract}

Keywords : Insomnia, Sleep Hygiene Program, older adult

\section{Introduction}

Sleep is a vital component of health. It is essential for mental and physical well being and is crucial for rejuvenation of the body. Impaired sleep quality can result in harmful effects on mental and physical well being. Impaired or disrupted sleep has been shown to cause poor concentration, reduced energy levels, altered immune function, poor wound healing, mood changes (increased impatience and irritability), increased risk of depression or anxiety, and a higher occurrence of accidents and falls, especially in the elderly. Sleep and sleep hygiene practices can be self-managed by each individual Hill et al., (2015).Insomnia is defined as difficulty initiating sleep, difficulty maintaining sleep, morning awakening, or sleep that is a chronic non-restorative or poor in quality associated with daytime impairment such as fatigue, memory impairment, social or vocational dysfunction, or mood disturbance. Insomnia is the number one sleep disorder complaint in older adults. Clinically significant insomnia is accompanied by significant distress or impairment that occurs for at least one month. Epidemiological studies show that the prevalence of insomnia increases steadily with ageDCSC, (2014).

Sleep is divided into non-rapid eye movement sleep (NREM) and rapid eye movement sleep (REM). NREM sleep is further subdivided into stage 1,2 and 3 based on unique electroencephalographic (EEG) and electromyelographic (EMG) criteriaHonkus, (2014). Stage 3 is of particular importance since it is a period of slow-wave EEG activity that correlates with the release of growth hormone. Selective experimentally-induced deprivation of stage 3 sleep has been associated with increased insulin resistance.1 REM sleep is characterized by the presence of rapid eye movements as noted on electrooculography (EOG) and is commonly referred to as dream sleep. Most individuals have a progression through these stages, starting with Stage 1, ultimately reaching REM sleep. Most individuals will cycle through this progression four to five times per night. Thus, they may have three to five REM (dream) episodes, but may not recall any of themHerscovici et al., (2016). 
In the study comparing in Europe, the US and Japan noted that the prevalence of insomnia symptoms was $37.2 \%, 27.1 \%$ and $6.6 \%$, respectivelyand Another study of older American women found that the prevalence of general insomnia symptoms also varied considerably by ethnic group, ranging from approximately $70 \%$ in African Americans and European Americans to 35\% for English-speaking Caribbean's or Haitians; race/ethnicity explained up to $20 \%$ of the variance of insomnia symptom prevalenceEllis etal., (2014). Sleep hygiene is a broad concept which has been described as "practicing behaviors that facilitate sleep and avoiding behaviors that interfere with sleep"Maston etal., (2014). Sleep hygiene practices can comprise behavioral and environmental factors. Behaviors conducive to sleep include regular exercise, regular bedtimes and rising times, and no daytime napping. Brown etal., (2015). Behaviors not conducive to sleep or use of stimulants such as caffeine or tobacco, engaging in exciting or emotionally upsetting activities prior to bedtime and the use of alcohol .Sleep hygiene practices also include environmental factors conducive to sleep. Environmental factors include a mattress and pillow that are comfortable as well as sleeping in an environment that has the proper darkness, sound and temperature levels based on a person's individual comfort levelMaston et al., (2014).

Sleep hygiene education aims to teach individuals about the impact of lifestyle habits such as diet, exercise and drug use and the influence of environmental factors e.g. light, noise and temperature . While these issues are unlikely to cause insomnia they may well exacerbate it. Studies generally advocate (1) the avoidance of caffeine and nicotine (both stimulants) in the 6 hours before bed; (2) the avoidance of alcohol around bedtime (alcohol may facilitate sleep onset but it tends to cause fragmentation of sleep and nightmares); (3) the avoidance of a heavy meal before sleep (although a light meal may be helpful); (4) the avoidance of exercise close to bed-time (even though in general exercise is helpful for sleep); and (5) the minimization of noise, light and excessive heat during the sleep period. Sleep hygiene also includes information concerning age-appropriate sleep duration to ensure realistic expectations(Singer \& Nanda, 2015).

Community programs for elderly should promote a wide range of knowledge and support services needed to prevent impaired or disrupted sleep has been shown to cause poor concentrationdue to chronic disease and deterioration of general functioning of the older person. The elderly also need special attention in community health, because of continuous increasing numbers, changes in society and the need to find effective ways for promoting their health. The nurse who provides care for older adults plays a central role in reducing the negative consequences of insomnia through a systematic approach for diagnosis, evaluation, and management of insomnia. Therefore, insomnia among elderly warrants thorough attention from a nurse who provides care for older adults (NCSDR, 2014).

\section{Significance:}

Many factors contribute to sleep patterns, including sleep hygiene practices. Maintaining consistent bed times and awakening times have been shown to promote the circadian rhythm of sleep, enabling the brain and body to know when to sleep and when to awaken Brown, et al., (2015). Regular exercise can promote increased total sleep time and depth of sleep (increased slow-wave sleep) as well as decreasing sleep onset latency (Stepanski \& Wyatt, 2013). Conversely, exercise within 2 to 3 hours of sleep may delay sleep onset Youngstedt, et al., (2012).Caffeine and nicotine are both considered stimulants that will cause the release of neurotransmitters, which, in turn, can cause a longer sleep onset latency Brown, et al., (2015). Additionally, heavy smokers can experience acute withdrawal during sleep, resulting in decreased slow-wave sleep and subsequent daytime sleepiness Zhang et al., (2016).In Egypt, a recent study found that $33.4 \%$ of elderly people in Alexandria experienced insomnia Saber,(2015). Also, another study in Egypt found that the prevalence of insomnia among institutionalized older people in Cairo was $36.4 \%$. In another study by Reid et al., (2014) a total number of 1503 elderly from 11 primary care settings, they found a prevalence of insomnia to be $45 \%$.

\section{Aim of the study:}

The aim of this study was to evaluate the effect of a sleep hygiene program for older adults through:

1. Assessing the older adult knowledge \&practices regarding the day time behavior \&environmental factors that effects on a sleep.

2. Developing and implementingsleep hygiene programs for older adult,according to the health needs and sleep problems,

3. Evaluating the effect of thesleep hygiene program on improving the day time behavior of older adults and their knowledge, practices and environmental factors that affect on a sleep.

\section{Research hypotheses:}

The sleep hygiene program will improve older adult knowledge \& their practices regarding the daytime behavior and factors that affect on a sleep. 


\section{Subjects and Methods: \\ Research design:}

A quasi-experimental design was used to achieve the aim of the study.

Settings:

This study was conducted at Dar El Safa \& Dar Elmarwa geriatric homes in Heliopolis area. This setting was chosen for its high density with a total number (124). It composed of two buildings each of them consists of three floors. Dar El Safa for stable cases \& Dar Elmarwa for criticalcases.

\section{Sample:}

A purposive sample was used to conduct this study. The sample size was $67(25$ male and 42 female)assuming that the older adult in the previous mentioned setting from the total 124, The sample size was calculated by using EPI info software program version 6.04.It was based on the prevalence of insomnia among the elderly in this study, which was $33.6 \%$ Abd Alla, (2014) with inclusion criteria, their aged 60 years and more, day time consequence of poor sleeping, free from psychiatric disorders and dementia.

\section{The tool was used in this study for data collection, namely a structured interview questionnaire $\&$ the Pittsburgh sleep quality index (PSQI):}

Part I: A structure interview questionnaire which included the demographic characteristics of older adult regardingage, gender, level of education,current occupation, maritalstatus, monthly income.

Part II :History of chronic disease and day time problems caused by inadequate sleep it involved questions about type of chronic disease, number of medications used daily, day time problems caused by inadequate sleep as fatigue, daytime sleepiness,stress,and dysfunction.

Part III: Sleep hygieneknowledge and practices as stated by older adult scale( Lacks etal.,1989) is an instrument that measures awareness of sleep hygiene and current practices it divided into two section , the first measure their knowledge about sleep hygiene regarding the day time behavior as ( daytime napping,smoking, exercises, sleep medication,regular bed time and rising time, meal before bed time\& watching TV at bed ), score The eight items were rated from zero to 3, (with 0corresponding to no problem at all and 3 to very serious problem. The elderly subjects are asked to grade the severity ofthese complaints $($ absent $=0$, mild $=1$, severe $=$ 2 , and very severe $=3$ ). Elderly subject who had a total score 6 points orhigher was considered as a positive case for insomnia, also evaluate their knowledge about environmental factors that could affect sleeping such as a mattress and pillow that are comfortable as well as sleeping in an environment that has the proper darkness, noisy and temperature levels based on a person's individual comfort level and evaluate caffeine knowledge by asking responds to identify common foods , beverages, and nonprescription drugs, responds answer yes \& no, the score ranged from 0-1 which correspond to the percentage of correct answers contain caffeine knowledge or environmental factors. The practices section contain the sleep hygiene practice asking about number of days per week0-7 that they have had the experience or engagedin the activity listed(such as take a nap,Smoke more than one pack of cigarettes, drink beverages containing caffeine, take medications for sleep, light , noise, comfortable temperature in bed room, regular bed time and rising time, mattress and pillow that are comfortable, exercise before bed time, relax before bed) .The scoring one point for each day of the activity from 0,indicating never,to7,indicating every day or night, the total score ranged from $0-11$ with higher scores less indicative of good sleep hygiene practices.

PartIV: The PittsburghSleep Quality Index (PSQI) 1989); the Sleep Impairment Index Morin (1993).It's a self report questionnaire designed to measure sleep quality and disturbance over a month period ago, and included questions regarding subjective sleep quality, sleep latency, sleep duration, sleep efficiency, sleep disturbance and daytime dysfunction. Each item is rated from 0-3 scale with 0 indicating no difficulty and 3 indicating severe difficulty. The global score has ranged from 0-18 with higher score denoting not adequate sleep quality. The global score has a cutoff - of $>6$ that has been used to distinguish not adequate sleeper and Score $<6$ refers to adequatesleepers.

Validity test:five experts from Faculty Members of Community Health Nursing department were asked to revise the tool for its content validity.

Reliability test: the tool was modified accordingly Gronbach Alpha coefficients test was used to ascertain the reliability of the tool $(\mathrm{r}=0.087)$

\section{Preparatory phase:}

\section{Methods}

\section{Pilot study:}

A pilot study was conducted on 10elderly to test the content, clarity and time needed to fill the tool as a pre-test. According tothe pilotstudy, modification was done. The pilot study sample was excluded in the study sample. 


\section{Ethical consideration:}

Each elderly were informed about the purpose and benefits of the study, and then oral consent was obtained before starting the data collection. Strict confidentiality was ensured throughout the study process. The study subjects were assured that all data was used only for research purpose and the elderly were informed of the rights to refuse or withdraw at any time with no consequences.

\section{Fieldwork:}

After official permissions to carry out the study, the aim of the study was explained to the selected subjects. The study was carried out along a period of 6 months starting from the beginning of July 2016 till the end of December 2016 until the sample size attained and apply all the program phases.

The average time consumed to fill tool was 30-45 minutes. The previously mentioned settings were visited by the researchers two days/week Saturday and Thursdayfrom 10.00 am to $2.00 \mathrm{pm}$.

\section{The programs for older adult included the four phases:}

Preparatory phase: The agreement for the participation of the subjects was taken after aims of the study have explained to the elderly they were given as an opportunity to refuse to participate. The researcher was reassuring the elderly that all the issues discussed confidential, used for research purpose only and for the sake of his loved one.

Planning phase:General objective of the program was to improve the older adult knowledge, practices as stated by them \&behavior regarding thedaytime. Determine learning the contents of the programregards sleep hygiene knowledge, caffeine,medication adherence and factors affect sleep. Additionally, nutrition, exerciseand sleep hygiene practices, the teaching methods used was discussion, role play, demonstration, pictures\& using simple Arabic language. Educational media was used as a laptop and video.

\section{Implementation phase:}

Through group discussion, the researcher discussed with the elderly the following:

1. The program was applied through (5) sessions two hours /week. The sessions were implemented every week in a special room in the pre-mentioned setting for a (30-45) minutes for each session over a period of two weeks and each session contained (8-12 elderly). Then data were collected twice after 2 weeks posttest Started with a summary of the previous session, and the objectives of the new one. The educational sessions lasted through 6 months.

2. The programcovered the elderly knowledge regarding sleep hygieneas,do not go to bed until are drowse,wake up within an hour of normal wake-up time every day, including weekends, do not take naps, If take a nap, limit it to less than an hour early in the afternoon, expose to sunlight or other bright lights in the morning, do not drink alcohol later than 2 hours before bedtime, do not consume caffeine after about 4 p.m. or within 6 hours prior to bedtime, do not smoke within several hours before bedtime, exercise regularly, but not within 2 hours of bedtime, make bedroom easier to sleep in and have a bedtime ritual, Turn down the lights before bedtime, make sure bed is comfortable, and minimize noise, use earplugs if neighbors are noisy, If usually snack before bedtime, have a light carbohydrate snack with a small amount of fluid, such as milk., caffeine knowledge , awareness of food, beverages, or drugs that are disruptive to sleep \& The practice covered how many nights per week they engage in activities that promote or inhibit sleep .Routine exercise( Scheduling exercise too close to bedtime), 30 minutes per day, 3 to 4 days a week can improve sleep duration, sleep onset latency, and quality of sleep.

Evaluation phase: Evaluate the effect by using the pre/post phases of the sleep hygieneprogram on improving elderly knowledge, practices and factors that affect their sleep.Statistical analysis:

The collected data were organized, categorized, tabulated and analyzed. Data were presented in tables and charts using numbers and percentage, statistics and associations were done using mean, standard deviation SD, $t$ - test and p- value, Significant of the result: no Significant if p->0.05, Significant if $p-<0.05$ and Highly Significant if $\mathrm{p}-<0.001$.

\section{Results}

Table 1: Demographic characteristics of the studied elderly $(\mathrm{N}=67)$

\begin{tabular}{|ll|l|l|}
\hline Items & No & \% \\
\hline Age & $60-$ & 17 & \\
$\bullet$ & $65 \leq 70$ & 50 & 25.4 \\
\hline Mean $=$ & $\mathbf{6 6 . 5} \pm \mathbf{3 . 2 9}$ & 25 & 74.6 \\
\hline Sex & Male & 25 & \\
$\bullet$ & Female & 42 & 62.3 \\
\hline
\end{tabular}




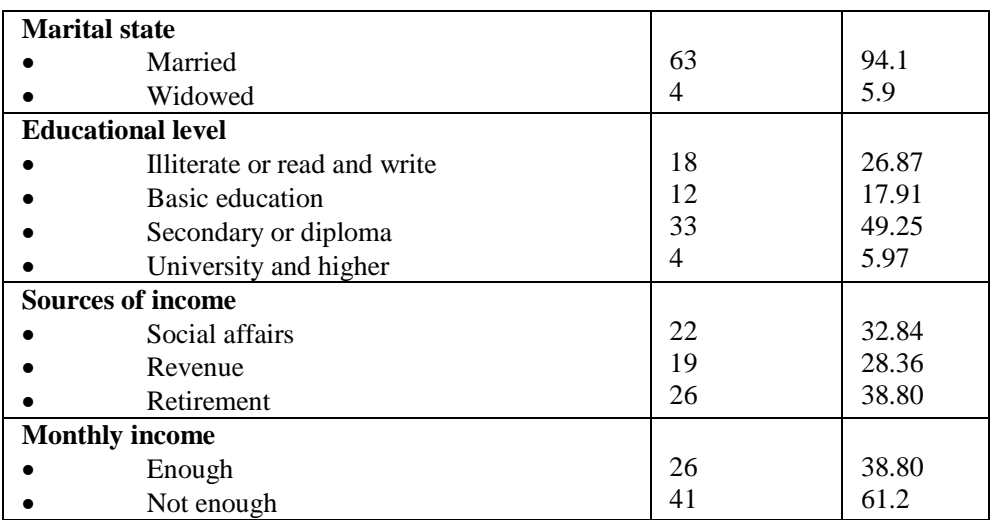

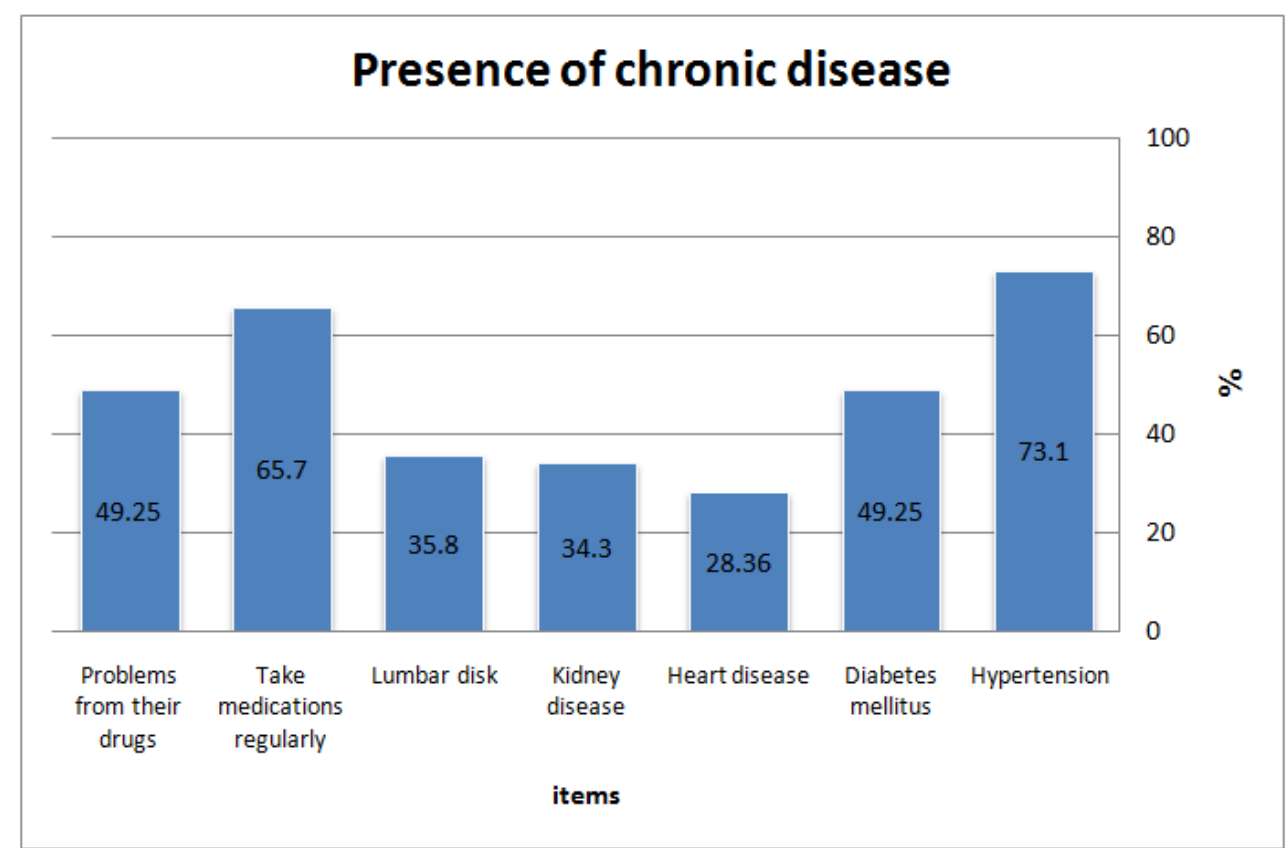

Figure (1): Percentage distribution of the elderly according to their medical history $(\mathrm{N}=67)$.

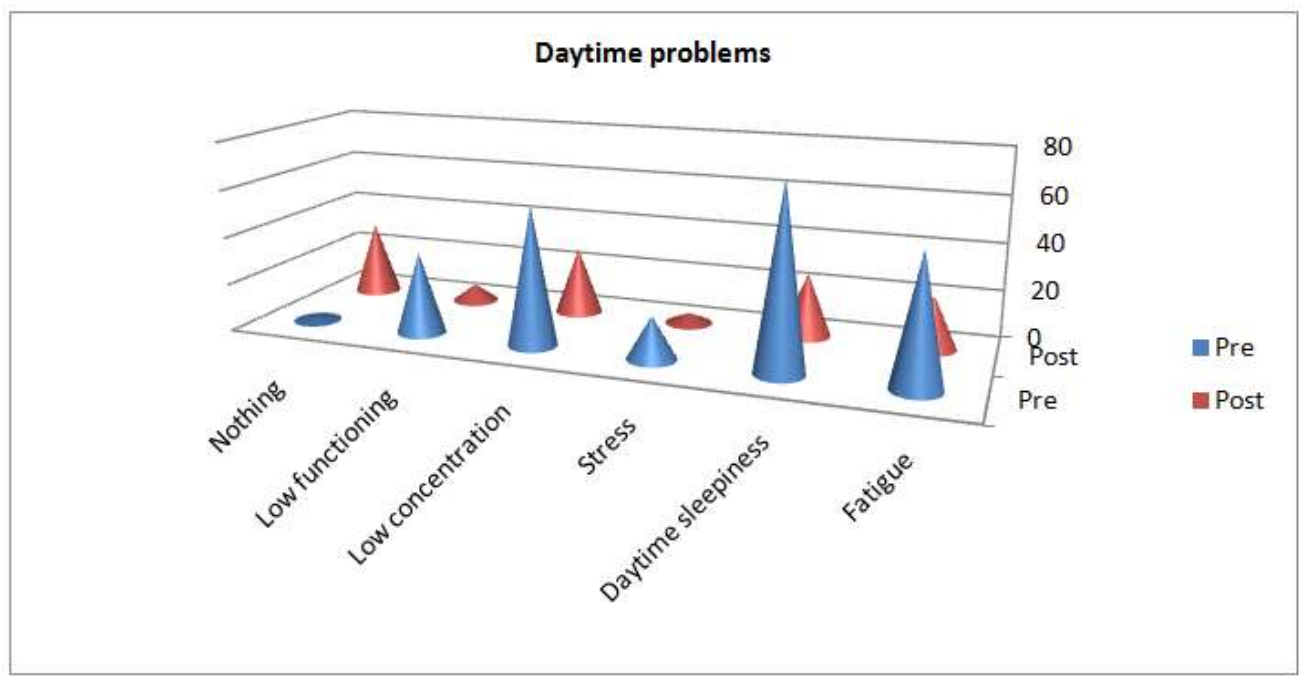

Figure (2): Percentage distribution of the elderly according to daytime problems caused by inadequate sleep pre and post program $(\mathrm{N}=67)$

According to research hypothesis sleep hygiene program will improve older adult knowledge $\&$ their practices regarding the daytime behavior (Table 2-8). 
Table 2: Percentage distribution of the elderly according to correct knowledge regards sleep hygiene pre and post program $(\mathrm{N}=67)$.

\begin{tabular}{|c|c|c|c|c|c|}
\hline \multirow{3}{*}{ Sleep hygiene knowledge } & \multicolumn{4}{|c|}{ Correct sleep hygiene knowledge } & \multirow[t]{3}{*}{$\mathbf{P}$} \\
\hline & \multicolumn{2}{|c|}{ Pre $(n=67)$} & \multicolumn{2}{|c|}{ Post $(n=67)$} & \\
\hline & $\mathbf{N}$ & $\%$ & $\mathbf{N}$ & $\%$ & \\
\hline \multicolumn{6}{|l|}{ Day time behavior } \\
\hline Day time napping. & 12 & 17.9 & 46 & 68.6 & $0.00^{*}$ \\
\hline Smoking. & 54 & 80.5 & 56 & 83.5 & $0.001 * *$ \\
\hline Sleep medication & 8 & 11.9 & 50 & 74.6 & $0.00 * *$ \\
\hline Exercise & 16 & 23.8 & 54 & 80.5 & $0.00 * *$ \\
\hline Regularwaking up & 45 & 67.1 & 60 & 89.5 & $0.001 * *$ \\
\hline Regular bedtime and rising time & 61 & 91 & 66 & 98.5 & 0.058 \\
\hline Mealbefore bed time. & 52 & 77.6 & 67 & 100 & $0.00 * *$ \\
\hline Watching T.V. at bed & 7 & 10.4 & 28 & 41.7 & $0.00 * *$ \\
\hline Total mean score of sleep hygie & \multicolumn{2}{|c|}{$56.05 \pm 3.7$} & \multicolumn{2}{|c|}{$17.4 \pm 1.7$} & $\mathbf{0 . 0 0 * *}$ \\
\hline
\end{tabular}

\section{$*_{p}<0.05$ (significant) $\quad * * P<0.01$ (high significant)}

The total score can range from 14-42, with higher scores indicating less sleep hygiene knowledge.

Table 3: Distribution of correct level knowledge regards caffeineknowledge\& environmental factors pre and post program $(n=67)$.

\begin{tabular}{|c|c|c|c|c|c|}
\hline \multirow{3}{*}{ Correct level knowledge } & \multicolumn{4}{|c|}{ Correct caffeine knowledge } & \multirow[t]{3}{*}{$\mathrm{P}$} \\
\hline & \multicolumn{2}{|c|}{ Pre $(n=67)$} & \multicolumn{2}{|c|}{ Post $(n=67)$} & \\
\hline & $\mathbf{N}$ & $\%$ & $\mathbf{N}$ & $\%$ & \\
\hline \multicolumn{6}{|l|}{ Caffeine knowledge } \\
\hline Different types of cane (Cola, 7-up or sprite, Pepsi) & 37 & 55.2 & 67 & 100 & $0.00 * *$ \\
\hline Energy drinks\# & 12 & 17.9 & 59 & 88 & $0.00 * *$ \\
\hline Lemonade & 43 & 64 & 66 & 98.5 & $0.001 * *$ \\
\hline Regular coffee\&tea\# & 36 & 53.7 & 50 & 74.6 & $0.00 * *$ \\
\hline \multicolumn{6}{|l|}{ Environmental factors } \\
\hline Proper darkness. & 12 & 17.9 & 59 & 88 & $0.00 * *$ \\
\hline Temperature level during the sleep period & 15 & 22.3 & 56 & 83.5 & $0.00 * *$ \\
\hline Exercises. & 7 & 10.4 & 56 & 83.5 & $0.00 * *$ \\
\hline Noise & 10 & 14.9 & 48 & 71.6 & $0.00 * *$ \\
\hline Mattress and pillow & 43 & 64 & 66 & 98.5 & $0.001 * *$ \\
\hline Total mean score of caffeine knowledge & \multicolumn{2}{|c|}{$28.67 \pm 17.46$} & \multicolumn{2}{|c|}{$59.56 \pm 7.57$} & $0.00 * *$ \\
\hline
\end{tabular}

\# containing caffeine *p 0.05 (significant) $* * P<0.01$ (high significant)

The total score can range from 0-100 with higher scores indicating better caffeine knowledge.

Table 4: mean scores, levels of sleep hygiene practices as reported by the studied elderly pre and post program $(\mathrm{N}=67)$

\begin{tabular}{|c|c|c|c|c|}
\hline \multirow[t]{2}{*}{ Sleep hygiene practices } & \multicolumn{2}{|c|}{ Post-pre difference } & \multirow[t]{2}{*}{ Paired-t } & \multirow[t]{2}{*}{$\mathbf{P}$} \\
\hline & Mean & SD & & \\
\hline \multicolumn{5}{|l|}{ Day time behavior } \\
\hline Take a nap & 2.38 & 1.20 & 17.12 & $0.000 *$ \\
\hline Smoke more than one pack of cigarettes. & 0.18 & 0.92 & 1.74 & 0.085 \\
\hline Drink beverages containing caffeine & 2.16 & 1.39 & 13.40 & $0.000 *$ \\
\hline Take medications for sleep & 1.50 & 1.67 & 7.80 & $0.000 *$ \\
\hline \multicolumn{5}{|l|}{ Environmental factors: } \\
\hline Exercise strenuously within 2 hours of bed time. & 1.10 & 1.68 & 5.70 & $0.000 *$ \\
\hline Relax before bed time & -2.08 & 1.27 & -14.17 & $0.000 *$ \\
\hline Light. & 1.32 & 1.11 & 10.23 & $0.000 *$ \\
\hline Noise. & 1.73 & 0.89 & 16.85 & $0.000 *$ \\
\hline Regular bedtime and rising time. & -1.74 & 1.53 & -9.85 & $0.000 *$ \\
\hline Proper temperature in bed room. & -2.08 & 1.27 & -14.17 & $0.000 *$ \\
\hline Mattress and pillow that are comfortable & 2.16 & 1.39 & 13.40 & $0.000 *$ \\
\hline Total mean score of sleep hygiene practice & $\begin{array}{l}\text { Pre } \\
\text { Mean } \pm \text { SD } \\
52.80 \pm 9.16\end{array}$ & $\begin{array}{l}\text { Post } \\
\text { Mean } \pm \text { SD } \\
21.20 \pm 7.92\end{array}$ & 37.98 & $0.000 *$ \\
\hline
\end{tabular}

$* p<0.05$ (significant) $* * P<0.01$ (high significant)

The total score can range from 0-126 with higher scores indicating less healthy sleep hygiene practices.

Table 5: Statistical differences of the mean values of PSQI Component and total scores of the studied elderly pre and post program $(\mathrm{N}=67)$.

\begin{tabular}{|l|l|l|l|}
\hline \multirow{2}{*}{ PSQI Components scores } & Phase & \multirow{2}{*}{ P } \\
\cline { 2 - 3 } & $\begin{array}{l}\text { Pre } \\
\mathbf{M} \pm \text { SD }\end{array}$ & $\begin{array}{l}\text { Post } \\
\mathbf{M} \pm \text { SD }\end{array}$ & \\
\hline Subjective sleep quality. & $1.58 \pm 0.63$ & $0.82 \pm 0.41$ & $0.00^{* *}$ \\
\hline
\end{tabular}




\begin{tabular}{|l|l|l|l|}
\hline Sleep latency. & $2.4 \pm 0.56$ & $1.48 \pm 0.64$ & $0.00^{* *}$ \\
\hline Sleep duration. & $1.85 \pm 0.61$ & $1.09 \pm 0.6$ & $0.00^{* *}$ \\
\hline Sleep efficiency. & $1.82 \pm 0.72$ & $0.82 \pm 0.7$ & $0.00^{* *}$ \\
\hline Sleep disturbances. & $1.97 \pm 0.36$ & $1.25 \pm 0.43$ & $0.00^{* *}$ \\
\hline Daytime dysfunction. & $1.82 \pm 0.52$ & $0.86 \pm 0.4$ & $0.00^{* *}$ \\
\hline Total Global PSQI Score & $\mathbf{1 1 . 5 3} \pm \mathbf{2 . 2}$ & $\mathbf{6 . 3 3} \pm \mathbf{2 . 4}$ & $\mathbf{0 . 0 0 * *}$ \\
\hline
\end{tabular}

$* \mathrm{p}<0.05$ (significant) $* * \mathrm{P}<0.01$ (high significant)

Table 6: Statistical differences of sleep latency, sleep Efficiency, and Daytime Naps as reported by the studied sample pre and post program $(n=67)$.

\begin{tabular}{|c|c|c|c|}
\hline \multirow[t]{2}{*}{ Sleep parameters } & \multicolumn{2}{|l|}{ phase } & \multirow[t]{2}{*}{$\mathbf{P}$} \\
\hline & Pre $\mathrm{M} \pm \mathrm{SD}$ & $\begin{array}{l}\text { Post } \\
\mathrm{M} \pm \text { SD }\end{array}$ & \\
\hline Sleep latency (min). & $50 \pm 25$ & $21 \pm 13$ & $0.00^{* *}$ \\
\hline Day time Naps (no./wk.) & $4.50 \pm 1.71$ & $2.12 \pm 1.26$ & $0.000 *$ \\
\hline Total time in bed (hours) & $7.88 \pm 1.7$ & $8.0 \pm 1.04$ & 0.33 \\
\hline Total sleep time (hours) & $5.44 \pm 1.0$ & $6.44 \pm 0.96$ & $0.00 * *$ \\
\hline Sleep efficiency (\%) & $69.88 \pm 7.9$ & $80.57 \pm 6.88$ & $0.00 * *$ \\
\hline
\end{tabular}

$* \mathrm{p}<0.05$ (significant) $* * \mathrm{P}<0.01$ (high significant)

Table 7: Correlation between elderly total mean score of sleep hygiene knowledge and sleep hygiene practice and their global PSQI score.

\begin{tabular}{|l|l|l|l|l|}
\hline \multirow{2}{*}{ Items } & \multicolumn{2}{|l|}{$\begin{array}{l}\text { Total mean score of sleep hygiene } \\
\text { knowledge }\end{array}$} & $\begin{array}{l}\text { Total mean score of sleep hygiene } \\
\text { practice }\end{array}$ \\
\cline { 2 - 5 } & R & P & R & P \\
\hline $\begin{array}{l}\text { Global PSQI Score } \\
\text { Pre- intervention. }\end{array}$ & 0.178 & 0.127 & $0.473^{* *}$ & 0.000 \\
Post- intervention & 0.100 & 0.395 & $0.681^{* *}$ & 0.00 \\
\hline
\end{tabular}

R: Pearson's correlation coefficient.

Table 8: Relation between demographic characteristics of the studied elderly and sleep hygiene practice percentage of change

\begin{tabular}{|c|c|c|c|c|c|c|c|c|}
\hline \multirow[t]{3}{*}{ Items } & \multicolumn{6}{|c|}{ Sleep hygiene practice change } & \multirow[t]{3}{*}{$\mathrm{X} 2$} & \multirow[t]{3}{*}{$\mathbf{P}$} \\
\hline & \multicolumn{2}{|c|}{$\begin{array}{ll}\text { Not } \\
n=33\end{array}$ adequate } & \multicolumn{2}{|c|}{$\begin{array}{l}\text { Adequate } \\
\mathrm{n}=34\end{array}$} & \multicolumn{2}{|c|}{$\begin{array}{l}\text { Total } \\
\mathrm{n}=67\end{array}$} & & \\
\hline & $\mathbf{N}$ & $\%$ & $\mathbf{N}$ & $\%$ & $\mathbf{N}$ & $\%$ & & \\
\hline $\begin{array}{l}\text { Age (years): } \\
60- \\
65 \leq 70\end{array}$ & $\begin{array}{l}10 \\
23\end{array}$ & $\begin{array}{l}30.3 \\
69.7\end{array}$ & $\begin{array}{l}7 \\
27\end{array}$ & $\begin{array}{l}20.5 \\
79.4\end{array}$ & $\begin{array}{l}17 \\
50\end{array}$ & $\begin{array}{l}25.3 \\
74.6\end{array}$ & 0.835 & 0.360 \\
\hline $\begin{array}{l}\text { Sex: } \\
\text { Male } \\
\text { Female }\end{array}$ & $\begin{array}{l}12 \\
21\end{array}$ & $\begin{array}{l}36.3 \\
63.7\end{array}$ & $\begin{array}{l}13 \\
21\end{array}$ & $\begin{array}{l}38.3 \\
61.7\end{array}$ & $\begin{array}{l}25 \\
42\end{array}$ & $\begin{array}{l}37.3 \\
62.6\end{array}$ & 0.025 & 0.874 \\
\hline $\begin{array}{l}\text { Marital status: } \\
\text { Married. } \\
\text { Widowed. }\end{array}$ & $\begin{array}{l}32 \\
1\end{array}$ & $\begin{array}{l}96.7 \\
0.3\end{array}$ & $\begin{array}{l}31 \\
3\end{array}$ & $\begin{array}{l}91.1 \\
8.8\end{array}$ & $\begin{array}{l}63 \\
4\end{array}$ & $\begin{array}{l}94 \\
6\end{array}$ & 1.001 & 0.317 \\
\hline $\begin{array}{l}\text { Education: } \\
\text { Illiterate or Read \& write. } \\
\text { Basic education. } \\
\text { Secondary or diploma. } \\
\text { University }\end{array}$ & $\begin{array}{l}8 \\
7 \\
15 \\
3\end{array}$ & $\begin{array}{l}24.2 \\
21.1 \\
45.4 \\
9.3\end{array}$ & $\begin{array}{l}10 \\
5 \\
18 \\
1\end{array}$ & $\begin{array}{l}29.4 \\
14.7 \\
52.9 \\
2.9\end{array}$ & $\begin{array}{l}18 \\
12 \\
33 \\
4\end{array}$ & $\begin{array}{l}26.8 \\
17.9 \\
49.2 \\
5.9\end{array}$ & 1.814 & 0.6118 \\
\hline $\begin{array}{l}\text { Chronic diseases: } \\
\text { Yes. } \\
\text { No. }\end{array}$ & $\begin{array}{l}33 \\
- \\
\end{array}$ & $\begin{array}{l}100 \\
--\end{array}$ & $\begin{array}{l}25 \\
9\end{array}$ & $\begin{array}{l}73.5 \\
26.4\end{array}$ & $\begin{array}{l}58 \\
9\end{array}$ & $\begin{array}{l}86.6 \\
13.4\end{array}$ & 10.091 & $0.001 * *$ \\
\hline
\end{tabular}

\section{Results}

The results Shows that the age of the studied elderly ranged between $60 \leq 70$ years, with the mean $\mathbf{6 6 . 5}$ \pm 3.29, \&62.7\% were females. Table(1) also reported that $49.2 \%$ of them with secondary education and $94.1 \%$ was married. As regards to the source of income shows that $38.8 \%$ was the retirement, followed by $32.8 \%$ depends on the social affairs. Finally, $61.2 \%$ of the studied elderly their monthly income was not enough.Regarding to the Presence of chronic disease the current resultsfigure(1) Illustrates that $73.1 \%$ had hypertension, followed by $65.7 \%$ take medications regularly, diabetes mellitus and problems from their drugs represented equal proportion among the studied elderly $49.2 \%, 35.8 \%$ from them had lumber disc, $44.3 \%$ had kidney disease and $28.3 \%$ with heart disease.

Figure (2): Represents the percentage of day time problems caused by inadequate sleep pre and post program. Pre- program there were high percentages of day time problems particularly day time sleepiness, low concentration, fatigue, low functioning \& stress ( $76.1 \% \& 58.2 \% \& 53.7 \%, 34.3 \& 17.9 \%$ respectively), while 
these problems was decrease in their percentage and improved post- program phase to $(26.8 \%, 28.3 \%, 22.3 \%$, $7.4 \% \& 4.4 \%$ respectively). It was also noted that all day time problems showed highly statistical significant improvement post program phase at $\mathrm{P}<0.01$.

Table (2): Represents the number and percentage of correct knowledge regarding sleep hygiene of the studied elderly pre and post program. It showed highly statistical significant differences in all items of day time behavior at $\mathrm{P}<0.01$ except one item which was regular bed time and rising time.

Table (3): Indicates the number and percentage of correct level knowledge regardingcaffeine knowledge of the studied elderly pre and post program. At the pre-program phase the studied elderly didn't know that lemonade, different types of cane, regular coffee \& tea and energy drinks $(64 \%, 55.2 \%, 53.7 \%$ \& $17.9 \%$ respectively) containing caffeine. It was improved to $98.5 \%, 100 \%, 74.6 \% \& 88 \%$ respectively)at the post- program phase, all caffeine knowledge items revealed highly statistical significant differences at $\mathrm{P}<0.01$. The table also showsthe number and percentage of environmental factors affected sleep of the studied elderly pre and post program.At the pre-program phase the studied elderly noted that $(64 \%)$ had inadequate sleep due to uncomfortable of mattress and pillow and $(22.3 \%)$ due to temperature level during the sleep period. This result was improved to (98.5\% \&83.5\% respectively) at the post program phase,all environmental factors items revealed highly statistical significant differences at $\mathrm{P}<0.01$.

Table (4):reveals that there were statistically significant differences between the mean and standard deviation regarding levelsof sleep hygiene practices(day time behavior and environmental factors)pre and post program for each item at $\mathrm{p}<0.05$ except in one item which was smoke more than one pack of cigarettes.

Table (5): shows that there were highly statistically significance between the mean values and standard deviation of PSQI components and total scores of the studied elderly pre \& post program at $\mathrm{P}<0.05$.

Table (6): Shows that there were highly statistically significant differences in mean scores and standard deviation of sleep parameters and(sleep latency, total sleep time \& sleep efficiency) at $\mathrm{p}<0.01$. The table also illustrated statistically significant differences in mean scores and standard deviation of sleep parameters and day time naps at $p<0.05$. There were no statistically significant differences in mean scores and standard deviation of sleep parameters and total time in bed at $\mathrm{p}>0.05$.

Regarding the correlation between elderly' sleep hygiene knowledge and sleep hygiene practice and their Global PSQI Score pre and post program, table (7) indicates highly statistically significant between the score of sleep hygiene practice and global PSQL Score at $\mathrm{p}<0.01$ and the pre $(\mathrm{R}=0.473)$ and post $(\mathrm{R}=0.681)$ program phases. The table also indicates no statistically significant relation between elderly' sleep hygiene knowledge and their Global PSQI Score at $\mathrm{p}>0.05$ and the pre $(\mathrm{R}=0.078)$ and post $(\mathrm{R}=0.100)$ program phases. Concerning the relation between demographic characteristics of the studied elderly and sleep hygiene practice percentage of change, table (8) reveals that no statistically significant relations between any of elderly' demographic characteristics and sleep hygiene practice percentage of change at $\mathrm{P}>0.05$ except in one item which was chronic disease.

\section{Discussion}

Human need sleep just like food and water. Older adults need 7-8 hours sleep at night to have a normal physiologic function during the day (Ancoli\&Israel, 2015) When people get older, they need less sleep than younger adults, as the elderly, in their 60s, need 30-60 minutes less than adults in their 20s Reid etal., (2014). The quality of night sleep decreases with age and $30 \%$ of the elderly may experience chronic insomnia. Sleep hygiene means improving behavioral and environmental factors that ameliorate sleep. A good sleep at night can promote daytime alertness Byles etal., (2015)Concerning the demographic characteristics of the studied elderly, their age ranged between 60 and 70 years, with mean $66.5 \pm 3.29$ years. This study agree with Bellia et al.,(2013)in a study of 900 elderly found that prevalence rates of sleep problems among individuals aged 60 years and above across the USA, Western Europe, and Japan to be 56\%, 31\%, and 23\%, respectively, while epidemiological surveys have shown that approximately 13-33\% of Australian elderly have reported frequent difficulties in initiating or maintaining sleep.

The present study revealed that about two thirds of the studied elderly were females; it may reflect a higher prevalence of sleep problems among women. These findings confirm previous observation made by Bloom, et al; (2011)in a study of assessment and management of sleep disorders in older persons reported that, onepossible contributing factor placing women at increased risk for sleep difficulties are changes related to menopause. In fact, sleep difficulty is one of the hallmark symptoms of menopause, with approximately $25-50 \%$ of women undergoing menopause reporting sleep complaints compared to approximately $15 \%$ of the general population.Also most of the studied elderly were married. This result disagrees with a study done by Mousavi etal., (2012), aboutPrevalence and associated factors of insomnia syndrome in the elderly residing in Kahrizak Nursing Homeconcluded that the elderly with marital life satisfaction had more optimal sleep hygiene. Healthy relationship may improve sleep pattern, by inducing feeling of safety and security. 
The current study findings about half of the studied elderly were secondary or diploma education. A study conducted by Dollander, (2014) with aim of evaluating sleep quality and quality of life among elderly showed the significant relationship between educational status with sleep quality and quality of life. He also concluded that education for the elderly and focusing on this issue has played a basic role in the reduction of the complaints over sleep disorders. Finally, In a study by Byles etal., (2015) on 3097 persons in Iran aged 60 years and older, the results showed that sleep patterns were significantly related to educational attainment, life satisfaction, self- perceived health status and physical function status. They also found that women had longer sleep latency and fewer hours of sleep than men.In the current study it was observed that about two thirds of the studied sample their monthly income was not enough. This finding concurred with a study by Leng et al., (2014) examined the prevalence and correlates of sleep problems among elderly. This study have examined an array of factors in relation to sleep problems, with these problems being higher among unemployed individuals, those of older age, those with low level of education and those of low income and socioeconomic status. Also, from the point of view of the researcher these results may be due to retirement and cost of treatment of chronic diseases.Regarding medical history of the studied elderly revealed that the majority of them had chronic disease and the most common disease were hypertension, diabetes mellitus, heart disease and kidney disease. This result is incongruent with Fries et al., (2015) and Bellia et al .,(2013)in a study ofpredictors of falls and hip fractures in Michigan nursing homes who reported that the prevalence of main disease was as follows hypertension $27.3 \%$, arthritis $27 \%$,diabetes $12.7 \%$, and coronary artery disease $11.4 \%$ that sleep difficulties were not related to aging itself but instead were related to medical and psychiatric disorders and related health burdens. Department of Health and Human Services, (2016) reported that recent investigations have shown a growing association between sleep disturbance and the occurrence of cardiovascular disorders, strokes, loss of cognitive functions and memory, and dementia.

The present study findings about two thirds of the studied elderly mentioned that they took regular medications and about half of them had problems from their dugs. These findings are in agreement with (Ancoli\&Israel,2015) who performed a study about Insomnia in the elderly in Australia reported that with advancing age several changes occurs that can place one at risk for sleep disturbances including increased prevalence of medical conditions and increased medication use. In accordance with this, a study conducted by the researcher in the same study setting found that insomnia have statistically significant association with total number of daily medications Benloucif etal., (2014). From the point of the researcher use of medications is usual among elderly due to the higher frequency of chronic diseases and most of these medications are wellknown to cause sleep disturbances. Also, the study shows that about half of the studied elderly had hypertension and take medication regularly like antihypertensive drugs.In accordance with this, a study in Egypt conducted by Hood et al., (2014) revealed that the majority of sample had excessive daytime sleepiness; and there were high percentage of complications caused by sleep disturbance in as headache, stress and low concentration. Bad sleep quality can impact psychological and physical health of older adults. These results may be due to that drugs contain diuretics' that interrupted their sleeping by go to the bathroom many times at night.

The finding of this study indicated that there were high percentage of day time problems caused by inadequate sleep as reported by the studied elderly particularly fatigue, day time sleepiness, stress and low concentration. This result is incongruent with( Foley et al., 2009) in their study In a National Institute on Aging study of over 9,000 persons aged 65 years and older, they found that problems with sleep organization in elderly patients typically include difficulty falling asleep, less time spent in the deeper stages of sleep, early-morning awakening and less total sleep time. Poor sleep habits such as irregular sleep-wake times and daytime napping may contribute to insomnia, low functioning and concentration, stress and fatigue can also interfere with sleep. Primary sleep disorders are more common in the elderly than in younger persons. From the point of the researcher evaluation of sleep problems in the elderly includes careful screening for poor sleep habits and other factors that may be contributing to the sleep problem. Formal sleep studies may be needed when a primary sleep disorder is suspected or marked daytime dysfunction is noted.

\section{According to research hypothesis sleep hygiene program will improve older adult knowledge \& their practices regarding the daytime behavior.}

Regarding the sleep hygiene knowledge (SHK)of the studied elderly, the mean sleep hygiene knowledge score pre-intervention exceeded half of the total obtainable score $56.05 \pm 3.7$ the total SHK. The results also showed highly statistical significant differences related knowledgein all items of day time behavior except one item which was regular bed time and rising times. Lindstrom etal., (2012), was conducted a cross-sectional study on 242 older adults in Sweden to investigate the sleep parameters using the Pittsburgh Sleep Quality Index and sleep treatment option. The results showed that participants gave incorrect answers to items related to taking a nap during daytime and the use of sleep medications. They also erroneously believed that performing active exercise or engaging in emotionally upsetting activities close to bed time didn't disrupt sleep, and more than $60 \%$ of the elderly did not think that using the bed for purposes other than sleep induced a negative impact on 
sleep which concurred with the current findings.Regarding caffeine knowledge before the program, it was generally incorrectly. Many elderly were aware that beverage such as energy drinks; regular coffee \& tea and chocolate contain caffeine. However, the other of the studied elderly did not know that different types of cane, lemonade, and analgesics also contain caffeine. This finding disagrees with Vander et al., (2016) who conducted their study in Hong Kong to examine whether sleep hygiene related factors are associated with sleep quality among elderly people. The findings of this study indicated that the knowledge about caffeine was generally adequate, with an average of $73 \%$ giving correct answers. This variation of caffeine knowledge may be due to differences in sample size, target population and setting of the study, as well as increased knowledge of elderly people due to current information technology and social media.

According to the current study findings, there were post-program statistically significant improvements in total score of elderly caffeine knowledge. This finding was expected since the questions from the caffeine knowledge pre-test and post-test came directly from the sleep hygiene education component of program. Additionally, the majority of the studied elderly were educated and this might play an important role in improving their caffeine knowledge.The results shows incorrectly knowledge for elderly related to environmental factors pre program and improved post program and all environmental factors items revealed highly statistical significant differences. In a study by Dogan et al, (2015)undertaken at a health service at a teaching hospital located in Campinas (SP), the author observed that the main factors elders mentioned as being responsible for the interruption of their night sleep were environmental factors (for example, loud noises and excessive light disturbance, take heavy meal before sleep and uncomfortable mattress and pillow).In addition to these factors, among elderly, 44\% referred to the noise caused by equipment placed near the bed, the noise caused by spouse who were generally in poor health or who were need to use the bathroom or the urinal. Excessive lighting was cited as an influential factor by $52 \%$, and environment noises were cited by $36 \%$

Concerning self reported sleep hygiene practice of the studied elderly, there were statistically significant differences between the mean and standard deviation regarding levels of sleep hygiene practice (day time behavior and environmental factors) pre and post program for each item. Similarly, results of a study conducted by Avidan (2015), about Sleep in the geriatric patient population in western countries revealed that the elderly who received sleep hygiene instructions for eight weeks showed considerable improvement in their sleep hygiene practice.Also, Cricco et al., (2011)who performed a survey about the impact of insomnia on cognitive functioning in older adults, found that, Caffeine use ( 1 or more drinks per day) was also common for the majority of participants. However, only one third or fewer had more than 3 caffeinated drinks per day. Caffeine doses of 100-400 mg can have sleeps disrupting effects, and the amount of caffeine in common a substance varies: cup of coffee (100-150 mg), or soda (35-50 mg), and chocolate bars (25 mg/ounce). Typical duration of caffeine activity is 3-5 hours for adults with some individuals experiencing effects for up to 10 hours. Because caffeine sensitivity is idiosyncratic and may be increased in older individuals due to age-related decreases in caffeine elimination, it is possible that low levels of consumption may have a detrimental impact on older insomniacs' sleep.

The studies of (Cole and Richards, 2013) indicate that environmental changes are very useful in treatment of sleep disorders and the improvement of sleep hygiene. Some wrong practices that may cause sleep disorders include late time exercise, drinking tea and eat heavy meal before bedtime, frequent naps during the day, watching exciting movies before bedtime, heat, extreme light and noise and staying in bed for a long time. The finding of this study indicated improvement in day time problems caused by inadequate sleep and improvement in their knowledge and practice regards sleep hygiene pre and post program. These results may be due to there were only few studies that have focused on improving sleep hygiene knowledge. So the researcher has derived findings from research studies on different population rather than elderly people to discuss some findings of the current study.It was hypothesized that after implementation of sleep hygiene program will improve older adult knowledge \& their practices regarding the daytime behavior. This hypothesis was supported by the current study findings which revealed that sleep hygiene program intervention had an effect on the Pittsburgh Sleep Quality Index (PSQI) components score and (PSQI) global score, which indicated significant improvement in the elderly' sleep quality as measured by the (PSQI). The same line with Ebersole, et al., (2012) and Goolsby (2016) in a study in London about toward Healthy agingstated that increase in self reported sleep duration in the sleep education group is higher than after program. This large increase in sleep duration may be in part due to the inclusion criteria of having habitual sleep duration of less than 6.5 hours a night, thus, improved sleep continuity may also have contributed to the self reported increase in sleep duration.

Also, in agreement with(Cheng \& Dizon 2014) in his study in Germany about Computerized cognitive behavioral therapy for insomnia, demonstrated that pre-post comparisons revealed a significant improvement in sleep quality of the studied older adults as measured by PSQI.Regarding to the current study findings there was statistically significant between mean values of sleep latency, sleep efficiency, and day time naps as reported by the studied sample pre and post program. It could predict shorter sleep latency, higher sleep efficiency and improvement of sleep quality for studied elderly post-intervention. It will be easier to change their life style 
because almost all participants live in retirement community, married, and need to change their behavior and lifestyle.Regarding the correlation between elderly' total mean score sleep hygiene knowledge and sleep hygiene practice and their Global PSQI Score pre and post intervention, the results indicates statistically significant positive correlations between the score of sleep hygiene practice and global PSQL Score at the pre and post intervention phases. The results also indicate no statistically significant correlation between elderly' sleep hygiene knowledge and their Global PSQI Score at the pre and post intervention phases.

These findings are consistent with a study conducted in Australia by (Edward \& Wang 2016) to examine the relationships between sleep knowledge, sleep practice and PSQI Score in a sample of 946 participants with age ranging from 16 years old to 50 years and older. The results of this study showed that there was a significant association between sleep practice and PSQI Score. As well as, there was no significant relationship between sleep knowledge and PSQI Score.Concerning the relation between demographic characteristics of the studied elderly and sleep hygiene practice the findings reveals no statistically significant relations between any of elderly' demographic characteristics and sleep hygiene practice percentage of change. This findings was disagree with(Christa and Jahchens ,2014)in a study about sleep disturbances and healthy sleep in North America, stated that a positive correlation between demographic characteristics and prevalence of sleep disturbance was observed in the case group after program. It congruent with Bellia, et al., (2013) who reported that positive correlation between demographic characteristics and prevalence of sleep disturbance was significantly higher in asthma group. Assessment is more possible differences between men and women of this study.

\section{Conclusion}

Based on the findings and research hypothesis of the present study, it can be concluded that:The designed sleep hygiene program had statistically significant improvement in elderly knowledge and practices. Indeed, there was no statistically significant correlation between elderly' sleep hygiene knowledge and their Global PSQI Score as sleep latency, sleep duration, sleep efficiency, sleep disturbances and day time dysfunction at the pre and post intervention phasesat $\mathrm{P}<0.05$.

\section{Recommendations}

In view of the study findings, it is recommended to conduct educational programs for elderly individuals with insomniatoimprove their sleep quality with more efforts to improve the awareness of the elderly regarding theimportance of sleep and the avoidance of risk factors of insomnia through posters, pamphlets, and booklets. Elderlyeducation on normal sleep related changes with emphasizing on the importance of sleep hygiene practices. Further research is needed to determine to what extent interventions to improve sleep can producebeneficial effects on QOL in the elderly.

\section{References}

[1]. Abd Alla, M.Z., (2014). The prevalence of insomnia among elderly in a rural area. Master thesis, Faculty of Medicine, Ain Shams University, Egypt, 2014.

[2]. Ancoli B. \&Israel S., (2015): Insomnia in the elderly: a review for the primary care practitioner. Sleep; 23(Suppl 1):S23-30.

[3]. Avidan A.Y., (2015): Sleep in the geriatric patient population. Semin Neurol. Mar; 25(1):52-63.

[4]. Bellia, V., Catalon F., Scichilone N., Incalzi, R.A., Spatafora M., Vergani C., \& Rengo F., (2013): Sleep disorders in the elderly with and without chronic airflow obstruction: the SARA study. Sleep in medical disorders. Sleep vol.26 (3): 318 -323.

[5]. Benloucif S., Orbeta L., Ortiz R., Janssen I., Finkel S.I., \& Bleiberg J., (2014): Morning or evening activity improves neuropsychological performance and subjective sleep quality in older adults. Sleep; 27(8):1542-51.

[6]. Bloom H.G., Ahmed I., Alessi C.A., Ancoli-Israel S., buysse D.J, Kryger M.H., Phillips B.A., F.C.C.P, Tborpy M.J, Vitiello M.V. and Zee P.C., (2011): Evidence-based recommendations for the assessment and management of sleep disorders in older persons. JAGS 57:761-789.

[7]. Brown, F. C., Buboltz, W. C., \& Soper, B., (2015). Development and evaluation of thesleep treatment and education program for students. Journal of American CollegeHealth, 54 (4), 231-237.

[8]. Byles J.E., Mishra G.D., Harris M.A., (2015): The experience of insomnia among older women. Sleep. Aug; 1:28(8):972-9.

[9]. Cheng S.K, \& Dizon J. (2014): Computerized cognitive behavioral therapy for insomnia: a systematic review and metaanalysis.PsychotherPsychosom. 81(4):206-16.

[10]. Christa J, \& Jahchens B. (2014): Sleep disturbances\& Healthy sleep .North America:Awsna publication.P:3-4.

[11]. Cole C. \& Richards K., (2013): Sleep disruption in older adults. Harmful and by no means inevitable, it should be assessed for and treated. Am J Nurs. May; 107(5):40-9.

[12]. Cricco M., Simonsick E.M., Foley D.J., (2011): The impact of insomnia on cognitive functioning in older adults. J Am Geriatr Soc; 49(9):1185-9.

[13]. Department of Health and Human Services U.S. (2016): Exercise: A guide from the National Institute on Aging. Report No.: NIH Publication No 01-4258.

[14]. Dollander M. (2014): Etiology of adult insomnia.Encephale.28(6):493-502.

[15]. Diagnostic Classification Steering Committee (DCSC) (2014). International classification of sleep disorders. 3rd edition. Rochester (NY): American Academy of Sleep Medicine; 2014.

[16]. Dogan O, Ertekin S, Dogan S. Sleep quality in hospitalized patients. J Clin Nurs. (2015) ;14(1):107-13.

[17]. Ebersole P., Hess P., Touhy T. and Jett K., (2012): Toward Healthy aging. Human Needs\& Nursing Response, Biological Maintenance Needs. Chapter (8), 7th Ed, Elsevier Mosby. PP. 178: 193. 
[18]. Edward K., Wang Y. (2016): Adequate sleep among adolescents in positively associated with health status and health - related behaviors.BMC Public Health; 6:59.

[19]. Fries B.E., James M.L., Szafara K.L., Wright G..T,\& Chervin R.D.: (2015): Insomnia and hypnotic use, recorded in the minimum data set, as predictors of falls. and hip fractures in Michigan nursing homes. J Am Geriatr Soc; 53(6):955-62.

[20]. Goolsby M.,(2016): AANP insomnia surveys: sleep uncovered. J Am Acad Nurse Pract. 18 (12):557-558

[21]. Hood B., Bruck D., \& Kennedy G., (2014): Determinants of sleep quality in the healthy aged: the role of physical, psychological, circadian and naturalistic light variables. Age Aging.; 33(2):159- 165.

[22]. Herscovici, S., Pe'er, A., Papyan, S., \& Lavie, P. (2016). Detecting REM sleep from thefinger: an automatics REM sleep algorithm based on peripheral arterial tone(PAT) and actigraphy. Physiological Measurement, 28(2), 129-140.

[23]. Hill, L. E., Cumming, R. G., Lewis, R., Carrington, S., \& LeCouteur, D. G. (2015). Sleep disturbances and falls in older people. The Journals of Gerontology,62(1), 62-66.

[24]. Honkus, V. L. (2014). Sleep deprivation in critical care units. Critical Care Nursing,26(3), 179-189.

[25]. Lindstrom V., Andersson K., Lintrup M., Holst G., \& Berglund J., (2012): Prevalence of sleep problems and pain among the elderly in Sweden. J Nutr Health Aging. 16(2): 180-3.

[26]. Leng Y., Wainwright N.W., Cappuccio F.P.(.2014): Self-reported sleep patterns in a British population cohort. Sleep Med 2014; 15: 295-302.

[27]. Mousavi F., Tavabi A., Iran-pour E., \& Golestan B. (2012): Prevalence and associated factors of insomnia syndrome in the elderly residing in Kahrizak Nursing Home, Tehran, Iran. Iran J Public Health. 41(1):96-106.

[28]. Ellis JG, Perlis ML, Neale LF, Espie CA, Bastien CH(2014). The natural history of insomnia: focus on prevalence and incidence of acute insomnia. J Psychiatr Res. 2014 Oct; 46(10):1278-1285. [PubMed: 22800714].

[29]. Foley DJ, Monjan AA, Brown SL, Simonsick EM, Wallace RB, Blazer DG (2009): Sleep complaints among elderly persons: an epidemiologic study of three communities. Sleep. 1995;18:425-32.

[30]. Redeker, N. S., Tamburri, T., \& Howland, C. L. (2013). Prehospital correlates of sleep in patients hospitalized with cardiac disease. Research in Nursing \& Health, 21, 27-37.

[31]. Reid, K.J., Zoran, M., Sanford, F., Judy, S., Robyn, G., Kathryne, H., et al(2014). Sleep: A Marker of Physical and Mental Health in the Elderly. American Journal of Geriatric Psychiatry. 2014; 14(10): 860-866. PMid:17001025 http://dx.doi.org/10.1097/01.JGP.0000206164.56404.ba

[32]. Saber, A.D.M. Insomnia among elderly in Alexandria(2015). Master thesis, High Institute of Public Health, Alexandria University, Egypt; 2015.

[33]. Stepanski, E. J., \& Wyatt, J. K., (2013). Use of sleep hygiene in the treatment of insomnia. Sleep Medicine Reviews, 7(3), 215225 .

[34]. Singer, C. \& Nanda, F.(2015). Sleep and Aging: Insomnia in the Geriatric Population. In: Attarian, H. P. and Schuman, C. (Eds.),Clinical Handbook of Insomnia: Current Clinical Neurology, (2nd Ed.). Humana Press: 2015; 137-149.

[35]. Lacks:Lacks P, Powlishta K.(1989). Improvement following behavioraltreatment for insomnia: clinical significance, longtermmaintenance and predictors of outcome. Behavior Therapy1989;20:117-134.

[36]. Maston, D. F., Bryson, J., \& Corwyn, R. (2014). Assessment of sleep hygiene using theSleep Hygiene Index. Journal of Behavioral Medicine, 29(3), 223-227.

[37]. Morin CM(1993) b.:Dysfunctional beliefs and attitudes about sleep among older adults with and without insomnia complaints. Psychology and Aging 1993;8(3):463-7. [MEDLINE: 94030738].

[38]. National Center on Sleep Disorders Research (NCSDR) (2014). Sleep in medical conditions:National sleep disorders research plan 2003. Retrieved December 11, 2013 from http://www.nhlbl.nih.gov/health/prof/sleep/res_plan/section4/section4e/html.

[39]. PSQI 1989: Buysse DJ, Reynolds III CF,Monk TH, Berman SB, Kupfer DJ. The Pittsburgh Sleep Quality Index: a new instrumentfor psychiatric practice and research. Psychiatry Research, 1989;28:193-213.

[40]. Van der Heijden K.B, Smits M.G. \& Gunning W.B. (2016): Sleep hygiene and actigraphically evaluated sleep characteristics in children with ADHD and chronic sleep onset insomnia. J Sleep Res.15(1): 55-62.

[41]. Youngstedt, S. D., O'Connor, P. J., \& Dishman, R. K. (2012). The effects of acute exercise on sleep: A quantitative synthesis [Electronic version]. Sleep, 20, 203- 214.

[42]. Zhang, L., Samet, J., Caffo, B., \& Punjabi, N. M. (2016). Cigarette smoking and nocturnal sleep architecture [Electronic version]. American Journal ofEpidemiology, 164(6), 529-537 